\title{
Antibacterial class is not obviously important in outpatient pneumonia: a meta-analysis
}

\author{
N. Maimon*, C. Nopmaneejumruslers ${ }^{\#}$ and T.K. Marras
}

ABSTRACT: The aim of the present study was to systematically compare outcomes between antibiotic classes in treating outpatient community-acquired pneumonia, with regard to antibacterials active against atypical organisms, as well as between various antibacterial classes with similar atypical coverage.

A meta-analysis was performed on randomised controlled trials of antibacterials for communityacquired pneumonia in outpatients aged $\geqslant 18 \mathrm{yrs}$. The studies were independently reviewed by two reviewers. Clinical success and mortality were compared between different oral antibiotic classes, and antibacterials with atypical coverage (macrolides and fluoroquinolones) were specifically compared with other antibacterials.

In total, 13 eligible studies involving a total of 4,314 patients were included. The quality of the studies was variable. Five studied macrolides and fluoroquinolones, three macrolides and $\beta$ lactams, three fluoroquinolones and $\beta$-lactams and two cephalosporins versus $\beta$-lactams/ $\beta$ lactamase inhibitors. No significant difference was detected regarding clinical success or mortality, regardless of atypical coverage or between antibacterial classes with similar atypical coverage.

It was not possible to demonstrate any advantage of specific antibacterials for mild communityacquired pneumonia in relatively healthy outpatients. The need for coverage of atypical pathogens in this setting was not apparent. In mild-to-moderate cases of outpatient-treated community-acquired pneumonia, it might be most appropriate to select antibacterials according to side-effects, patient preferences, availability and cost.

KEYWORDS: Antibiotic, community-acquired pneumonia, outpatient, treatment

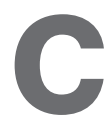

ommunity-acquired pneumonia (CAP) is common and associated with major morbidity, mortality and financial burden. The incidence of CAP is $1-5$ per 1,000 population, with a mortality of $3 \%$, and cost of US\$ 8,400 million annually in the USA [1]. It is the sixth leading cause of death, and the leading infectious cause of death [2]. It is likely that a minority of patients bear a majority of the morbidity and mortality and generate most of the treatment costs. More than $75 \%$ of patients are treated exclusively as outpatients, and typically these patients are aged $<65$ yrs, have no significant comorbid conditions and exhibit a mortality rate of $<1 \%$ [1]. A traditional paradigm for the outpatient management of CAP presumes that the aetiological organism is usually not recognised, and uses empirical oral antibacterial treatment directed toward the most likely causative pathogen. The clinician should also consider the severity of illness, patient age, clinical features, comorbid conditions, concomitant medications and epidemiological setting. The most likely causative bacteria in outpatients include Streptococcus pneumoniae, Mycoplasma pneumoniae, Haemophilus influenzae and Chlamydophila pneumoniae [2]. M. pneumoniae, C. pneumoniae and Legionella spp., sometimes grouped as atypical organisms, are often given special consideration because of the high frequency of infection with organisms of this group, and their sensitivity to macrolides, ketolides and fluoroquinolones, with resistance to other antibacterial classes [2].

Guidelines for the management of CAP vary in their antibacterial recommendations. The British Thoracic Society (BTS) recommends penicillin or amoxicillin, with erythromycin for atypical infections [3]. In contrast, the American Thoracic Society (ATS) and the Infectious Diseases Society of America (IDSA) recommend empirical macrolide or doxycycline therapy for most

\section{AFFILIATIONS}

*Pulmonology Institute, Soroka Medical Center, Faculty of Medicine, Ben-Gurion University of the Negev, Beersheba, Israel.

\# Mahidol University, Dept of Medicine, Division of Ambulatory Medicine, Faculty of Medicine, Siriraj Hospital, Bangkok, Thailand -University of Toronto, Dept of Medicine, University Health Network and Mount Sinai Hospital, Toronto, ON, Canada.

CORRESPONDENCE

T.K. Marras

Toronto Western Hospital

7E-452

399 Bathurst Street

Toronto

ON M5T 2S8

Canada

Fax: 14166035375

E-mail: ted.marras@utoronto.ca

Received:

August 202007

Accepted after revision:

January 082008

SUPPORT STATEMENT

N. Maimon was supported by the Princess Margaret Hospital

Foundation (Toronto, Canada) and held a clinical fellowship from the Sacta-Rashi Foundation (Kfar Hanoar Ben Shemen, Israel)

STATEMENT OF INTEREST A statement of interest for T.K. Marras can be found at www.erj.ersjournals.com/misc/ statements.shtml

European Respiratory Journal Print ISSN 0903-1936 Online ISSN 1399-3003 
patients, or a fluoroquinolone or $\beta$-lactam plus a macrolide in the presence of comorbid conditions [2]. The Canadian Infectious Diseases Society and the Canadian Thoracic Society recommend macrolide treatment for patients without modifiers, such as aspiration or chronic obstructive pulmonary disease [4]. The need for specific coverage against atypical organisms is a key difference between guidelines. Given the high reported incidence of atypical pneumonia among CAP cases, and the lack of in vitro activity of $\beta$-lactams against $M$. pneumoniae and C. pneumoniae, the utility of $\beta$-lactams in CAP treatment has been questioned [5]. Two recent high-quality meta-analyses have addressed questions related to this issue. BJERRE et al. [6] performed a meta-analysis investigating the efficacy of different antibacterials against outpatient-treated CAP (OCAP). Although they found no evidence to support a particular drug class, the results are limited by the small number of studies included (three trials), with a total of 622 patients, all of whom received antibiotics with activity against atypical organisms. This meta-analysis, therefore, does not address the question as to whether atypical coverage is important in OCAP, and provides no information regarding antibacterials other than macrolides and one of the fluoroquinolones. In a second relevant meta-analysis, MiLls et al. [7] compared the efficacy of antibacterials with activity against atypical pathogens versus $\beta$-lactams in nonsevere CAP. Their results are limited by the inclusion of only studies involving $\beta$ lactams in the group without atypical coverage, and of both inpatients and outpatients. Since the patients with in-patienttreated CAP probably differ significantly from those with OCAP, and because the results for in-patients and outpatients were not presented separately in this meta-analysis, its applicability to OCAP in general remains uncertain.

It was wondered whether the selection of antibacterial class for OCAP treatment in adults changes outcome, and whether the use of antibacterials effective against atypical organisms improves outcomes. Therefore, meta-analyses of prospective comparative trials of different oral antibacterials for OCAP treatment were performed. The primary objective was to assess whether or not antibacterials with coverage against atypical organisms provide improved clinical outcomes in OCAP. The secondary objective was to assess whether there were differences in outcome between patients treated with other pairs of antibacterial drug classes, as long as both comparators provided similar coverage against atypical organisms.

\section{METHODS}

Studies of adult OCAP treatment comparing different oral antibacterials were identified by searching MEDLINE (1966 to July 2007) and EMBASE (1980 to July 2007) using the terms "pneumo" (truncated), "bronchopneumonia" or "lower respiratory tract infection", combined with "outpatient" (truncated) and "administration", "oral administration" or "oral", and "randomized controlled trial", "controlled clinical trial", "randomized controlled trials", "random allocation", "double blind method" or "single blind method". Terms were searched as subject headings or text words and the search was limited to English language, human and adult studies. In addition, evidence-based medicine reviews, including the $A C P$ Journal Club, Cochrane Controlled Trials Register, Cochrane Database of Systematic Reviews and Database of Abstracts of
Reviews of Effects were searched. Bibliographies of all retrieved studies, guidelines for the treatment of CAP and numerous pertinent review articles were also studied. When there were inadequate data to decide whether or not a study was acceptable (e.g. did not clearly distinguish in-patients from outpatients), additional information was requested from the corresponding author or study sponsor.

The inclusion criterion was randomised double-blind trials comparing different antibacterial classes in OCAP. The primary outcome of interest was clinical cure or improvement, as defined by each study. Open-label, noncomparative and nonrandomised studies were excluded owing to potential important bias from the subjective nature of the primary outcome. Studies that combined in-patients and outpatients were also excluded, unless data were available to analyse the patient groups separately.

The studies were organised into four groups. For the primary objective and meta-analysis, trials that compared patients who received an antibacterial with activity against atypical organisms to those who received an antibacterial without activity against atypical organisms were reviewed. For the secondary objectives and meta-analyses, studies that compared different antibacterial drug classes were grouped, as long as both comparators provided similar coverage for atypical organisms (e.g. macrolides versus fluoroquinolones).

For the primary analysis, the intention-to-treat or modified intention-to-treat populations (those with CAP who had received at least one dose of study drug) were used. When the analysis was not clearly one of intention to treat, the clinically evaluable per protocol population were reviewed and included. When both early and late end-points were available, the earlier follow-up time (following completion of therapy) was used as test of cure. All-cause mortality, which would have included deaths until 28 days after treatment completion, was also reviewed since most studies followed patients until then. It had been hoped to assess additional endpoints that may have been of greater relevance to studies of OCAP, including time to symptom improvement or resolution, time away from work or school, duration of therapy, requirement for hospitalisation and infective complications, but these data were rarely available. Selected studies were reviewed independently by two investigators in order to rate study quality and collect data on methods, patient characteristics and outcomes according to a predetermined scheme adapted from HeINTJEs et al. [8], detailed in the Appendix. Discrepancies were resolved through consensus.

The results for the dichotomous outcome of interest (clinical success and mortality) were summarised using risk ratios as estimates of relative risk, with 95\% confidence intervals. Weightings and the summary estimates for each outcome were determined based on DerSimonian-Laird random effects models. Heterogeneity was evaluated using the MantelHaenszel method, and results were considered heterogeneous for a p-value of $<0.2$. The $\mathrm{I}^{2}$ statistic was used to assess the extent of inconsistency among results (how much of the total variation in apparent treatment effect was due to heterogeneity). The z-statistic was used to assess overall effect, and a pvalue of $\leqslant 0.05$ was considered significant. 


\section{RESULTS}

From $>2,300$ citations identified, 103 potentially eligible citations (93 from the literature review and 10 from reference lists), whose abstracts were reviewed, were retrieved. Of the 90 articles excluded, 22 were excluded because in-patients and outpatients could not be discerned, 20 because comparator antibacterials were of the same drug class, 16 because they included only in-patients, 10 because they were reviews, seven because they were uncontrolled, six because they included acute exacerbations of chronic bronchitis and nine for other reasons. The author or study sponsor was contacted for additional information regarding 22 articles. Two contacts indicated that additional data were unavailable, two confirmed that their studies included only outpatients and were thus eligible, and one provided data enabling calculation of outcomes among outpatients, thus permitting inclusion in the present analysis. Therefore, 13 studies were included (table 1) [9-21]. The two reviewers were in initial agreement on 340 $(82 \%)$ out of 416 entries regarding study methods and results, and $115(88 \%)$ out of 130 entries regarding study quality rating. All discrepancies were resolved by discussion. The 13 trials were performed in 36 countries between 1988 and 2002. A total of 4,314 patients were included, of whom 3,402 could be analysed (those without protocol violations and not lost to follow-up). For the primary objective and meta-analysis (atypical versus no atypical coverage), there were six eligible studies, three regarding macrolides versus $\beta$-lactams [15-17] and three of fluoroquinolones versus $\beta$-lactams [11, 13, 14], with a total of 1,193 patients. For the secondary objective and metaanalyses, there were seven eligible studies, five regarding macrolides versus fluoroquinolones $[9,12,18-20]$ and two of cephalosporins versus $\beta$-lactams/ $\beta$-lactamase inhibitors [10, 21 , with a total of 2,209 patients.

All study drugs were administered orally. All of the studies generally excluded patients with severe illness, usually defined by the need for hospitalisation and parenteral therapy. Other exclusion criteria were major cardiac, pulmonary, hepatic or renal dysfunction and immunocompromised states. The inclusions and exclusions resulted in participants who were younger and with a generally favourable prognosis compared to most in-patient CAP cohorts. Pharmaceutical companies sponsored 12 of the 13 studies. Five trials provided data on the intention-to-treat population. Three studies reported only on the clinically evaluable population, with an overall drop-out rate of $<20 \%$. Since all studies were blinded, the lack-of intention-to-treat data in some studies was not considered critical, and the data were, therefore, included. None of the included studies clearly reported exclusively ontreatment results. Table 1 presents the design and table 2 the outcomes of the included studies.

The mean age of patients was 49 yrs. Males composed $53 \%$ $(1,803$ out of 3,402$)$ of patients. Although none of the studies provided information regarding pneumonia severity index scores, all studies were designed to evaluate outpatient populations probably in pneumonia severity index risk class 1 or 2 [22]. The time of assessment varied between studies. Patients were assessed during treatment in 10 studies, and at the end of therapy in seven. In all studies, evaluation for cure occurred within 10 days following treatment completion. Study quality was moderate, with a median (range) score of
6.9 (6.0-8.2) out of a possible 10 (see Appendix). The most common deficiencies were in the descriptions of whether overall care was comparable between groups, whether groups were similar and whether randomisation was sound. In addition, most trials did not clearly present an intention-totreat analysis.

The overall rate of clinical cure or improvement was $90 \%$, and was reported for all trials. No significant difference between treatments was found in any study, nor any significant heterogeneity between studies. There was moderate, but nonsignificant, heterogeneity between studies for the primary analysis, atypical coverage versus no atypical coverage. The $\mathrm{I}^{2}$ statistic suggested that almost $50 \%$ of the moderate inconsistency observed in the primary analysis was due to heterogeneity (fig. 1a, table 3). This appears to be due to somewhat broader exclusion criteria and somewhat more rigorous outcome assessment criteria in three of the seven studies included in the primary analysis [11, 14,17]. Regarding the primary objective, no evidence was found that antibacterials active against atypical pathogens were superior to other antibacterials $(z=1.27 ; p=0.2 ;$ fig. 1a). Similarly, for the secondary objective, no evidence was found to support differences in rates of cure or improvement when comparing other antibacterials, including fluoroquinolones and macrolides $(z=0.19 ; p=0.85$; fig. $1 b$, table 3$)$, or cephalosporins versus $\beta$-lactam/ $\beta$-lactamase inhibitors $(z=0.46 ; p=0.65$; fig. $1 c$, table 3).

There were 24 deaths reported in five studies (mortality $0.7 \%$ ). This low mortality is in keeping with mild-to-moderate (nonsevere) CAP. There was no significant heterogeneity in either the primary analysis (atypical coverage versus no atypical coverage) or the secondary analysis (differences between drug classes with similar atypical coverage, macrolides versus fluoroquinolones). Regarding the primary objective, no differences in mortality were observed between patients who received coverage for atypical agents (fluoroquinolones or macrolides) versus other drugs $(\mathrm{z}=0.95 ; \mathrm{p}=0.34$; fig. $2 \mathrm{a}$, table 4). Similarly, for the secondary objective, no differences in mortality were observed between macrolides and fluoroquinolones $(z=0.39 ; p=0.70$; fig. $2 b$, table 4$)$.

\section{DISCUSSION}

It was not possible to demonstrate a difference between antibacterials, regardless of coverage of atypical organisms, in mortality or success in OCAP. Regarding the primary objective, there was no evidence supporting antibacterials active against atypical organisms (fluoroquinolones and macrolides) being superior to $\beta$-lactams in a variety of forms (cephalosporins, narrow-spectrum penicillins, and $\beta$-lactam $/ \beta$ lactamase inhibitors), all lacking activity against atypical pathogens. These data do not support a requirement for antibacterials that possess specific activity against atypical pathogens in OCAP, and also no differences in outcome could be identified, regardless of antibacterial class. Furthermore, regarding the secondary objective, it was also not possible to demonstrate any differences in outcome between drug classes with similar atypical coverage (including macrolides versus fluoroquinolones and cephalosporins versus $\beta$-lactam/ $\beta$-lactamase inhibitor combinations). 
TABLE 1 Characteristics of included studies of outpatient-treated community-acquired pneumonia

\begin{tabular}{|c|c|c|c|c|c|c|}
\hline $\begin{array}{l}\text { First author } \\
\text { [Ref.] }\end{array}$ & Study period & $\begin{array}{l}\text { Country } \\
\text { (centres) }\end{array}$ & $\begin{array}{l}\text { Duration } \\
\text { days }\end{array}$ & Drug/dose & Participants $\mathrm{n}^{\#}$ & $\begin{array}{c}\text { Outcome assessments } \\
\text { days }\end{array}$ \\
\hline FOGARTY [18] & 1996-1998 & USA (51) & 10 & $\begin{array}{l}\text { Moxifloxacin } 400 \mathrm{mg} \text { q.d. } \\
\text { Clarithromycin } 500 \mathrm{mg} \text { b.i.d. }\end{array}$ & $\begin{array}{l}194 \text { quinolone } \\
188 \text { macrolide }\end{array}$ & $16,24-45$ \\
\hline RAMIREZ [19] & 1996 & USA (54) & 10 & $\begin{array}{l}\text { Sparfloxacin } 200 \mathrm{mg} \text { q.d. } \\
\text { Clarithromycin } 250 \text { mg b.i.d. }\end{array}$ & $\begin{array}{l}167 \text { quinolone } \\
175 \text { macrolide }\end{array}$ & $4,20,38$ \\
\hline HoEfFKEN [12] & 1996-1998 & Multinational (50) & 10 & $\begin{array}{l}\text { Moxifloxacin } 200 / 400 \mathrm{mg} \text { q.d. } \\
\text { Clarithromycin } 500 \mathrm{mg} \text { b.i.d. }\end{array}$ & $\begin{array}{l}357 \text { quinolone } \\
174 \text { macrolide }\end{array}$ & $3-5,13-15,21-28$ \\
\hline Gotfried [9] & 1999-2000 & USA/Canada (51) & 7 & $\begin{array}{l}\text { Levofloxacin } 500 \mathrm{mg} \text { q.d. } \\
\text { Clarithromycin } 1000 \mathrm{mg} \text { q.d. }\end{array}$ & $\begin{array}{l}124 \text { quinolone } \\
128 \text { macrolide }\end{array}$ & $2-3,6-8,10,21-28$ \\
\hline MACFARLANE [17] & 1993-1994 & UK (14) & 7 & $\begin{array}{l}\text { Amoxicillin } 250 \mathrm{mg} \text { t.i.d. } \\
\text { Clarithromycin } 250 \mathrm{mg} \text { b.i.d. }\end{array}$ & $\begin{array}{l}212 \text { penicillin } \\
214 \text { macrolide }\end{array}$ & 8,15 \\
\hline FOGARTY [10] & 1998-2001 & USA (83) & 14 & $\begin{array}{l}\text { Ceftidoren } 200 / 400 \mathrm{mg} \text { b.i.d. } \\
\text { Amoxicillin/clavulanate } 125 / 875 \text { mg b.i.d. }\end{array}$ & $\begin{array}{l}301 \text { cephalosporin } \\
144 \text { penicillin }\end{array}$ & $3-5,7-10,16,21-28$ \\
\hline Higuera [21] & 1988-1991 & Multinational (31) & 10 & $\begin{array}{c}\text { Cefuroxime } 500 \mathrm{mg} \text { b.i.d. } \\
\text { Amoxicillin/clavulanate } 125 / 500 \mathrm{mg} \text { t.i.d. }\end{array}$ & $\begin{array}{l}55 \text { cephalosporin } \\
51 \text { penicillin }\end{array}$ & $3-5,11-13,24$ \\
\hline DonowITZ [11] & 1992-1995 & USA (74) & 10 & $\begin{array}{l}\text { Sparfloxacin } 200 \mathrm{mg} \text { q.d. } \\
\text { Cefaclor } 500 \mathrm{mg} \text { t.i.d. }\end{array}$ & $\begin{array}{c}168 \text { quinolone } \\
162 \text { cephalosporin }\end{array}$ & $3-5,17-23,31-45$ \\
\hline O'DoHERTY [14] & 1992-1993 & UK/USA (43) & $7-10$ & $\begin{array}{l}\text { Grepafloxacin } 600 \mathrm{mg} \text { q.d. } \\
\text { Amoxicillin } 500 \mathrm{mg} \text { t.i.d. }\end{array}$ & $\begin{array}{l}114 \text { quinolone } \\
111 \text { penicillin }\end{array}$ & $10-15,35-52$ \\
\hline Petitpretz [13] & 1997-1998 & Multinational (82) & 10 & $\begin{array}{l}\text { Moxifloxacin } 400 \text { mg q.d. } \\
\text { Amoxicillin } 1000 \text { mg t.i.d. }\end{array}$ & $\begin{array}{l}41 \text { quinolone } \\
40 \text { penicillin }\end{array}$ & $3-5,13-15,31-38$ \\
\hline
\end{tabular}

ER: extended release. ${ }^{\#}$ : at randomisation; $"$ : time after starting therapy.

Previous meta-analyses, although of high quality, have addressed somewhat different questions using different inclusion criteria [6, 7]. BJERRE et al. [6], although limiting their analysis to studies of outpatients, included studies in which all participants received therapy with atypical activity, making it impossible to address whether or not atypical coverage is helpful. Two of the three studies included compared two macrolides (clarithromycin versus erythromycin) and one of the studies (also included in the present analysis) compared a macrolide to a fluoroquinolone. To the meta-analysis of BJERRE et al. [6], the present study, therefore, adds an analysis of almost 1,200 patients in order to assess whether or not atypical therapy is useful in OCAP, an analysis of an additional 1,200 patients comparing macrolide versus fluoroquinolone therapy and analyses comparing other drug classes. Mills et al. [7] apparently included both in-patient and outpatient studies in their meta-analysis, and focused exclusively on whether atypical coverage is beneficial.

TABLE 2 Outcome of outpatient-treated community-acquired pneumonia by antibacterial class

\begin{tabular}{lccccc} 
& Subjects & Adverse events & Clinical success & Hospitalisation & Mortality \\
Quinolone & 1231 & $58(4.7)$ & $1071(87.0)$ & 4 & $13(1.0)$ \\
Macrolide & 1026 & $50(4.9)$ & $908(88.5)$ & NR & $6(0.6)$ \\
Penicillin & 558 & $21(3.8)$ & $521(93.4)$ & NR & $2(0.4)$ \\
Cephalosporin & 587 & $30(5.1)$ & $553(94.2)$ & $3(0.5)$ \\
\hline
\end{tabular}

Data are presented as $n$ or $n(\%)$. Data represent the total number of patients for whom each variable was available. NR: not reported. 
a)

\section{Study}

KINASEWITZ [16]

MACFARLANE [17]

DONOWITZ [11]

O'DOHERTY [14]

SALVAREZZA [15]

PetitPRetz [13]

Overall

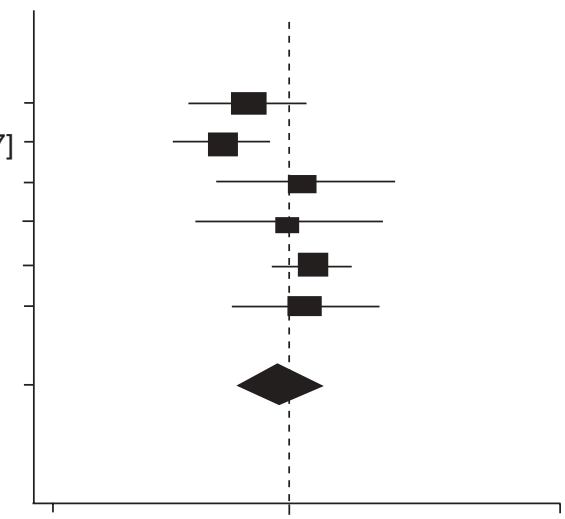

b)

\section{Study}

FOGARTY [18]

RAMIREZ [19]

HOEFFKEN [12]

GotFRIED [9]

SOKOL [20]

Overall

c)

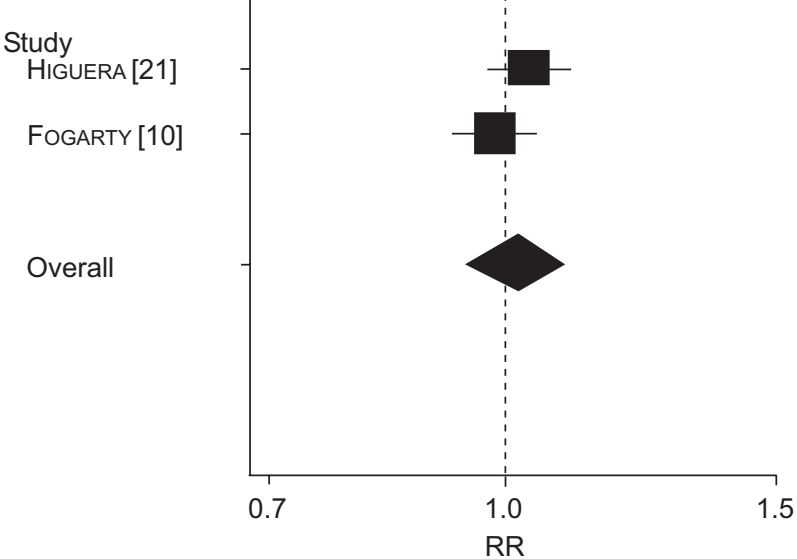

FIGURE 1. Clinical success in studies of outpatient-treated communityacquired pneumonia by empirical antibacterial therapy: a) atypical coverage (treatment) versus no atypical coverage (control); b) macrolides (treatment) versus fluoroquinolones (control); and c) cephalosporins (treatment) versus $\beta$-lactams $/ \beta$ lactamase inhibitors (control). Data are presented as risk ratio (RR; $\mathbf{\text { a }}$ (size reflects weighting)), using a random effects model, and 95\% confidence interval (horizontal bars). The centre of the diamond indicates the combined mean effect of the studies and its extremities the $95 \%$ confidence interval. ........ line of no effect. Risk ratios above that of the line of no effect favour controls. In testing for heterogeneity of the combined results that contributed towards the overall mean result were as follows. a) Chi-squared 9.41 (5 degrees of freedom (df); $p=0.09$ ), b) Chi-squared 4.34 (4 df; $p=0.36$ ) and c) Chi-squared 1.67 ( $1 \mathrm{df} ; \mathrm{p}=0.20)$. a) $\mathrm{I}^{2}=46.8 \%$, b) $\mathrm{I}^{2}=7.8 \%$ and c) $I^{2}=40.0 \%$. In testing for overall effect: a) $z=0.69(p=0.49)$, b) $z=0.19(p=0.85)$ and $c) z=0.43(p=0.66)$
The present study adds to that of MiLLs et al. [7] in several ways. First, it focused exclusively on outpatients, a group that is probably different from patients admitted with CAP. Intuitively, it might be assumed that, since in-patient-treated CAP has a higher mortality, it should be easier to detect a difference in outcomes with in-patients, and that studying cohorts with in-patients might improve the sensitivity of interventional trials in CAP. However, it is not clear that this can be stated with certainty. Outpatients and in-patients are assessed in different ways, and clinical trials comparing these groups may be designed differently. In addition, it may be difficult to design appropriate clinical end-points for both inpatients and outpatients in a single trial. For example, if the resolution of symptoms were chosen as the definition of clinical cure, it may be that very few in-patients reach this endpoint within a reasonable follow-up period, whereas complete resolution is probably more common in outpatients. Using the end-point of resolution of symptoms in a study of outpatients might, therefore, result in more patients reaching the endpoint, and therefore permit a more useful analysis. The present authors, therefore, believe that there is merit in performing a meta-analysis focusing on outpatients. Secondly, the present analysis of atypical coverage included two additional studies $[15,17]$, with a total of 486 patients, not included in the study of Mills et al. [7]. Thirdly, differences between other classes of antibacterials in OCAP were also assessed, in order to maximise guidance to clinicians. The present study adds significantly to previous meta-analyses, and its results are, in general, consistent with both previous meta-analyses.

Although the present confidence intervals for differences in effect were wide, the present authors do not believe that lack of power necessarily explains these results. There are several alternative explanations for the present findings. First, there may be a high incidence of self-limiting viral infections as a cause of mild CAP. Secondly, the natural history of atypical bacterial mild CAP, in most cases, is one of resolution with or without therapy, and antibiotic intervention may simply hasten resolution, an important outcome, but not one which could be adequately studied due to incomplete data availability. Thirdly, atypical bacterial CAP may be an asymptomatic co-infection, along with a clinically important pathogen that succumbs to $\beta$-lactams [5]. In OCAP, the possibility that the role of self-limiting viral infections is often underestimated and that of atypical bacterial pathogens often overestimated is consistent with a recent study of CREER et al. [23]. In this study, viral infections were highly prominent causes of lower respiratory tract infections, the most prevalent bacterial pathogen being S. Pneumoniae [23].

It is possible that undetected bias played a role in obscuring a positive outcome of atypical coverage. Based on this possibility, the sample sizes required to detect minimal clinically important differences in clinical success and mortality in OCAP were calculated using the method of two proportions [24]. Assuming a 90\% clinical success rate in controls, $>3,200$ patients per group would be required in order to detect a $2 \%$ benefit ( $92 \%$ clinical success) with the intervention, using a two-sided $\alpha$ of 0.05 and $80 \%$ power. If the minimal clinically important difference were $1 \%$, the required sample size would increase to $>13,000$ patients per group. Based on a baseline mortality of $0.7 \%,>6,700$ patients per group would be 
a)

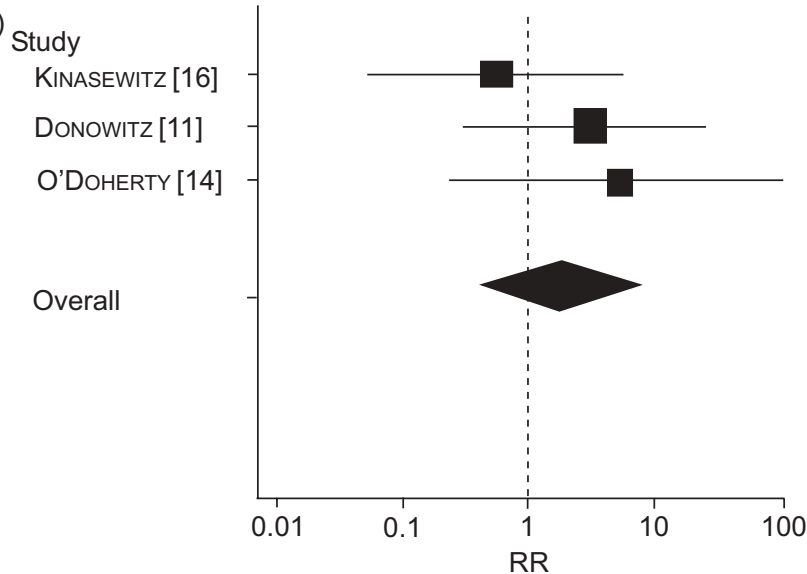

b)

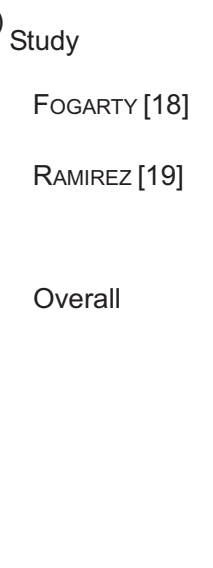

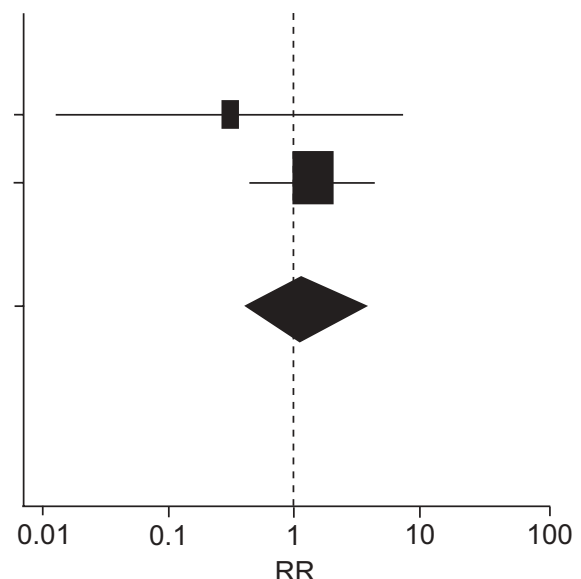

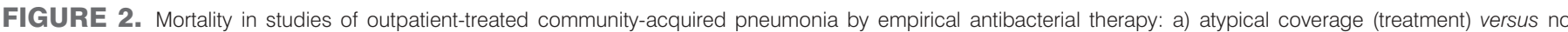

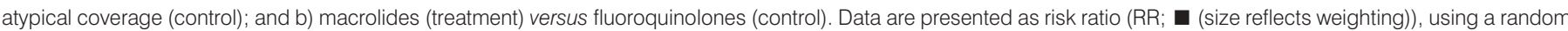

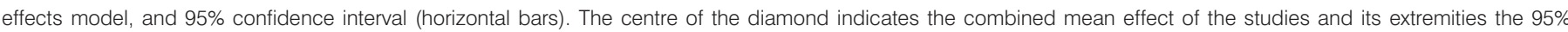

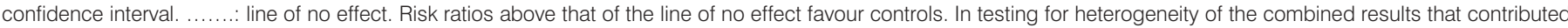

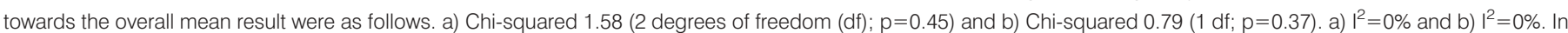
testing for overall effect: a) $z=0.77(p=0.44)$ and $b) z=0.39(p=0.70)$.

required in order to detect a decrease to $0.35 \%$ (a $50 \%$ relative reduction and $0.35 \%$ absolute reduction), using similar parameters. These estimates suggest that much more data than are currently available would be required in order to confidently address the outcomes under study. If the total number of patients in the present studies were too small to detect an important difference in outcomes that were present, the negative results would represent a type 2 error. Since outcomes are generally good in uncomplicated patients with mild OCAP, and the observed point estimates did not favour the intervention (atypical coverage), the present authors think that it is unlikely that larger studies could have demonstrated a large effect on clinical success and mortality. Questions regarding time to resolution of symptoms, however, remain more uncertain. Although heterogeneity between studies may call the results of a meta-analysis into question, the present authors

TABLE 3 Clinical success in studies of outpatient-treated community-acquired pneumonia and study weighting

\begin{tabular}{|c|c|c|c|c|}
\hline First author [Ref.] & $\begin{array}{c}\text { Treatment } \\
\mathrm{n} / \mathrm{N}\end{array}$ & $\begin{array}{c}\text { Control } \\
n / N\end{array}$ & Weight \% & $\operatorname{RR}(95 \% \mathrm{Cl})^{\#}$ \\
\hline \multicolumn{5}{|c|}{ Atypical versus no atypical coverage } \\
\hline MACFARLANE [17] & $174 / 214$ & $191 / 212$ & 21.13 & $0.90(0.83-0.98)$ \\
\hline DoNowITZ [11] & $122 / 168$ & $115 / 162$ & 11.37 & $1.02(0.89-1.17)$ \\
\hline O'DOHERTY [14] & $87 / 114$ & $85 / 111$ & 10.30 & $1.00(0.86-1.15)$ \\
\hline PetitPRetz [13] & $39 / 41$ & $37 / 40$ & 14.52 & $1.03(0.92-1.15)$ \\
\hline Overall & $482 / 599$ & $496 / 594$ & 100 & $0.98(0.93-1.04)$ \\
\hline \multicolumn{5}{|c|}{ Macrolide versus fluoroquinolone } \\
\hline FoGARTY [18] & 178/188 & $184 / 194$ & 34.82 & $1.00(0.95-1.05)$ \\
\hline RAMIREZ [19] & $145 / 175$ & $133 / 167$ & 8.40 & $1.04(0.94-1.15)$ \\
\hline HOEFFKEN [12] & $164 / 174$ & $336 / 357$ & 37.80 & $1.00(0.96-1.05)$ \\
\hline HiGUERA [21] & $55 / 55$ & $49 / 51$ & 50.33 & $1.04(0.97-1.11)$ \\
\hline FoGARTY [10] & $268 / 301$ & $130 / 144$ & 49.67 & $0.99(0.92-1.05)$ \\
\hline Overall & $323 / 356$ & $179 / 195$ & 100 & $1.01(0.95-1.08)$ \\
\hline
\end{tabular}

RR: risk ratio; $\mathrm{Cl}$ : confidence interval. ${ }^{\#}$ : the RR was calculated using a random effects model; " : treatment versus control. 


\begin{tabular}{|c|c|c|c|c|}
\hline KINASEWITZ [16] & $1 / 32$ & $2 / 35$ & 37.11 & $0.55(0.05-5.75)$ \\
\hline DoNOWITZ [11] & $3 / 168$ & $1 / 162$ & 40.45 & $2.99(0.30-27.53)$ \\
\hline O'DOHERTY [14] & $2 / 114$ & 0/111 & 22.43 & $4.87(0.24-100.30)$ \\
\hline RAMIREZ [19] & 0/175 & $1 / 167$ & 11.18 & $0.32(0.01-7.76)$ \\
\hline HOEFFKEN [12] & $5 / 174$ & $7 / 357$ & 88.82 & $1.47(0.47-4.55)$ \\
\hline Overall & $5 / 349$ & $8 / 524$ & 100 & $1.24(0.42-3.59)$ \\
\hline
\end{tabular}

RR: risk ratio; Cl: confidence interval. ${ }^{*}$ : the RR was calculated using a random effects model; $"$ : treatment versus control.

are confident that they have accurately interpreted the available data. No significant advantage or disadvantage was found with any oral treatment, the majority of studies found similar outcomes in both groups and there were no sources of heterogeneity between the studies. For these reasons, the present authors doubt that any important differences were missed based on the available data.

A major strength of the present study is the inclusion of only randomised prospective double-blind studies using only oral therapy exclusively in outpatients. The multinational origin of the studies, performed in 35 different countries, also increases its generalisability. The present results must, however, be interpreted in light of these same factors. The inclusions resulted in patients with mild pneumonia, reflected in the low mortality. It is, therefore, not possible to provide any guidance for the management of severe CAP, where the standard of care is hospitalisation and intravenous antibacterials. Therefore, the present results are only applicable to the subset of patients with mild CAP. Nevertheless, this subset makes up a major proportion of patients with pneumonia. Another factor to consider regarding generalisability stems from the paucity of information available regarding the referral source of the patients (primary care versus specialty practices versus urgent care centres). Even within the population of outpatients, there is an important spectrum of patients that could be better understood if this information were provided. However, focusing the present analyses on studies that contained only outpatients aims to minimise this type of limitation.

A limitation of the present work is that it was not possible to address whether or not there is a difference in recovery time between antibacterials. Comparing time to recovery is important in this setting, in which the majority of patients experience mild, often self-limiting, disease, and the rationale for treatment is to prevent complications and shorten illness duration. Unfortunately, data regarding time to clinical success or symptom improvement were not available. Data regarding need for hospitalisation and infective complications were also not systematically reported. The lack of adequate information regarding these very important outcomes is a critical limitation of the currently available controlled trials in OCAP. An additional limitation is that only initial antibacterial therapy could be reviewed due to the availability of clinical trials. It should be emphasised that antibacterial treatment should always be reassessed in a patient who shows signs of deterioration or failure to improve.

The present findings are in conflict with the ATS and IDSA guidelines, which state that all populations with CAP should be treated for possible infection with atypical pathogens [2]. The present findings tend to support the BTS guidelines [3], which consider S. pneumoniae the most important target of initial antibacterials. The BTS guidelines state that a policy aiming to always cover the atypical pathogens is inappropriate. Additionally, the present findings are in agreement with the recent study of CREER et al. [23], demonstrating the importance of viral infections and, among bacteria, a predominance of pneumococcus as a cause of lower respiratory tract infection. The present conclusions probably apply most closely to those patients referred to by the ATS and IDSA guidelines as outpatients who were previously healthy and without risk factors for drug-resistant $S$. pneumoniae. Generalising to patients with comorbidity or recent antibiotic use, even though some patients with these characteristics were included in the studies, is probably inappropriate.

The present results represent the best level of evidence currently available for addressing the selection of initial antibacterials for relatively healthy outpatients with mild community-acquired pneumonia. It appears that the outcome of outpatient-treated community-acquired pneumonia is generally good regardless of whether of not there is coverage for atypical agents, as long as there is coverage for Streptococcus pneumoniae. The present authors speculate that these results may be due to the fact that many cases of outpatient-treated community-acquired pneumonia are due to viral or other selflimiting pathogens. Thus the selection of antibacterials, in this context, should probably be based upon side-effect profile, price, physician and patient preferences, and resistanceinduction considerations.

\section{APPENDIX}

Selected studies were reviewed independently to rate study quality and collect data on methods, patient characteristics and outcomes according to a predetermined scheme [8] (table 5). 


\begin{tabular}{|c|c|c|c|c|c|c|c|c|c|c|c|}
\hline TAB & $\begin{array}{l}\text { Meth } \\
\text { pnes }\end{array}$ & $\begin{array}{l}\text { todological o } \\
\text { umonia }\end{array}$ & uality rating $s$ & ales for tria & of different & antibacteric & in out & tient-treated & community- & acquire & \\
\hline \multirow[t]{2}{*}{ [Ref.] } & \multirow[t]{2}{*}{$\operatorname{lnc} / \operatorname{Exc}^{\#}$} & \multirow{2}{*}{$\begin{array}{c}\text { Truly } \\
\text { randomised }\end{array}$} & \multirow{2}{*}{$\begin{array}{c}\text { Groups } \\
\text { comparable }^{+}\end{array}$} & \multirow{2}{*}{$\begin{array}{l}\text { Intervention } \\
\text { clear }^{5}\end{array}$} & \multirow{2}{*}{$\begin{array}{c}\text { Comparable } \\
\text { care }^{f}\end{array}$} & \multirow[t]{2}{*}{ Blinding ${ }^{\# \#}$} & \multicolumn{2}{|c|}{ Outcomes } & \multirow{2}{*}{$\begin{array}{c}\text { Follow-up } \\
\text { appropriate }^{\S \S}\end{array}$} & \multirow[t]{2}{*}{$\mathbf{I T T}^{f f}$} & \multirow[t]{2}{*}{ Total $^{\# \# \#}$} \\
\hline & & & & & & & Clear" & Appropriate $^{++}$ & & & \\
\hline$[18]$ & 1 & 0.5 & 0.5 & 1 & 0 & 1 & 1 & 0.33 & 1 & 0 & 6.33 \\
\hline$[12]$ & 1 & 0.5 & 0.5 & 1 & 0 & 1 & 1 & 0.67 & 1 & 0 & 6.67 \\
\hline [9] & 1 & 0.5 & 0.5 & 1 & 0 & 0.67 & 1 & 0.67 & 1 & 0 & 6.34 \\
\hline$[16]$ & 1 & 0.5 & 0 & 1 & 0 & 1 & 1 & 0.67 & 1 & 0.5 & 6.67 \\
\hline$[15]$ & 0.5 & 1 & 0.5 & 1 & 0 & 0 & 1 & 0.33 & 1 & 1 & 6.33 \\
\hline$[17]$ & 1 & 0.5 & 1 & 1 & 0 & 0.67 & 0.5 & 0.33 & 1 & 0 & 6 \\
\hline [13] & 1 & 0.5 & 0.5 & 1 & 0 & 1 & 1 & 0.33 & 1 & 1 & 7.33 \\
\hline
\end{tabular}

Inc: inclusion; Exc: exclusion; ITT: intention to treat. ${ }^{\#}$ : 1 : clearly defined; 0.5 : inadequately defined; ${ }^{\bullet}: 1$ : yes (clearly described, including concealed potential allocation); 0.5 : unclear; ${ }^{+}:$: : yes; 0.5 : inadequately described; 0 : obvious differences; ${ }^{5}$ : 1 : interventions clearly defined and applied via standardised protocol; 0 : intervention poorly or not defined; $f: 1$ : care programmes, other than trial options, identical; 0.5 : clear but trivial differences; 0 : not mentioned or important differences; ${ }^{\# \#: ~ 1: ~ p a t i e n t s, ~}$ treatment providers and outcome assessors blinded to treatment group; 0.67: two of three blinded; 0.33: one of three blinded; 0 : no blinding or not mentioned; $"$ ": 1 ; outcomes clearly defined; 0.5 : inadequately defined; 0 : not defined; ${ }^{++}$: 1 : outcomes include clinical success, mortality and length of stay; 0.67 : includes any two; 0.33 : includes any one; 0 : none; ${ }^{\S \S}$ : 1 : follow-up active and of appropriate duration ( $>3$ weeks); 0.5 : active, inadequate duration; 0 : not active or not defined; $f f: 1$ : outcomes of

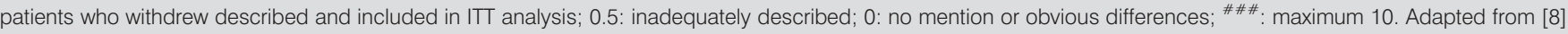

\section{REFERENCES}

1 Niederman MS, McCombs JS, Unger AN, Kumar A, Popovian R. The cost of treating community-acquired pneumonia. Clin Ther 1998; 20: 820-837.

2 Mandell LA, Wunderink RG, Anzueto A, et al. Infectious Diseases Society of America/American Thoracic Society consensus guidelines on the management of communityacquired pneumonia in adults. Clin Infect Dis 2007; 44: Suppl. 2, S27-S72.

3 British Thoracic Society Standards of Care Committee. BTS guidelines for the management of community-acquired pneumonia in adults. Thorax 2001; 56: Suppl. 4, iv1-iv58.

4 Mandell LA, Marrie TJ, Grossman RF, Chow AW, Hyland RH. Canadian guidelines for the initial management of community-acquired pneumonia: an evidencebased update by the Canadian Infectious Diseases Society and the Canadian Thoracic Society. Clin Infect Dis 2000; 31: 383-421.

5 Lieberman D, Schlaeffer F, Boldur I, et al. Multiple pathogens in adult patients admitted with communityacquired pneumonia: a one-year prospective study of 346 consecutive patients. Thorax 1996; 51: 179-184.

6 Bjerre LM, Verheij TJM, Kochen MM. Antibiotics for community acquired pneumonia in adult outpatients. Cochrane Database Syst Rev 2004; 2: CD002109.

7 Mills GD, Oehley MR, Arrol B. Effectiveness of $\beta$ lactam antibiotics compared with antibiotics active against atypical pathogens in non-severe community acquired pneumonia: meta-analysis. BMJ 2005; 330: 456-460.
8 Heintjes E, Berger MY, Bierma-Zeinstra SMA, Bernsen RMD, Verhaar JAN. Exercise therapy for patellofemoral pain syndrome. Cochrane Database Syst Rev 2002; 4: CD003472.

9 Gotfried MH, Dattani D, Riffer E, et al. A controlled, double-blind, multicenter study comparing clarithromycin extended-release tablets and levofloxacin tablets in the treatment of community-acquired pneumonia. Clin Ther 2002; 24: 736-751.

10 Fogarty CM, Cyganowski M, Palo WA, Hom RC, Craig WA. A comparison of cefditoren pivoxil and amoxicillin/clavulanate in the treatment of communityacquired pneumonia: a multicenter, prospective, randomized, investigator-blinded, parallel-group study. Clin Ther 2002; 24: 1854-1870.

11 Donowitz GR, Brandon ML, Salisbury JI, et al. Sparfloxacin versus cefaclor in the treatment of patients with community-acquired pneumonia: a randomized, doublemasked, comparative, multicenter study. Clin Ther 1997; 19: 936-953.

12 Hoeffken G, Meyer HP, Winter J, Verhoef L. The efficacy and safety of two oral moxifloxacin regimens compared to oral clarithromycin in the treatment of communityacquired pneumonia. Respir Med 2001; 95: 553-564.

13 Petitpretz P, Arvis P, Marel M, Moita J, Urueta J. Oral moxifloxacin vs high-dosage amoxicillin in the treatment of mild-to-moderate, community-acquired, suspected pneumococcal pneumonia in adults. Chest 2001; 119: 185-195.

14 O'Doherty B, Dutchman D, Pettit R, Maroli A. Randomised double-blind comparative study of grepafloxacin and 
amoxicillin in the treatment of patients with communityacquired pneumonia. Chemotherapy 1997; 40: 73-81.

15 Salvarezza CR, Mingrone H, Fachinelli H, Kijanczuk S. Comparison of roxithromycin with cefixime in the treatment of adults with community-acquired pneumonia. J Antimicrob Chemother 1998; 41: 75-80.

16 Kinasewitz G, Wood RG. Azithromycin versus cefaclor in the treatment of acute bacterial pneumonia. Eur J Microbiol Infect Dis 1991; 10: 872-877.

17 MacFarlane JT, Prewitt J, Gard P, Guion A. Comparison of amoxicillin and clarithromycin as initial treatment of community-acquired lower respiratory tract infections. $\mathrm{Br}$ J Gen Pract 1996; 46: 357-360.

18 Fogarty CM, Grossman C, Williams J, Haverstock D, Church D. Efficacy and safety of moxifloxacin versus clarithromycin for community-acquired pneumonia. Infect Med 1999; 16: 748-763.

19 Ramirez J, Unowsky J, Talbot GH, Zhang H, Townsend L. Sparfloxacin versus clarithromycin in the treatment of community-acquired pneumonia. Clin Ther 1999; 21: 103-117.
20 Sokol WJ Jr, Sullivan JG, Acampora MD, Busman TA, Notario GF. A prospective, double-blind, multicenter study comparing clarithromycin extended-release with trovafloxacin in patients with community-acquired pneumonia. Clin Ther 2002; 24: 605-615.

21 Higuera F, Hidalgo H, Feris J, Giguere G, Collins JJ. Comparison of oral cefuroxime axetil and oral amoxycillin/clavulanate in the treatment of community-acquired pneumonia. J Antimicrob Chemother 1996; 37: 555-564.

22 Fine M, Auble TE, Yealy DM, et al. A prediction rule to identify low-risk patients with community-acquired pneumonia. N Engl J Med 1997; 336: 243-250.

23 Creer DD, Dilworth JP, Gillespie SH, et al. Aetiological role of viral and bacterial infections in acute adult lower respiratory infection (LRTI) in primary care. Thorax 2006; 61: 75-79.

24 Browner WS, Newman TB, Cummings SR, Hulley SB. Estimating sample size and power: the nitty gritty. In: Hulley SB, Cummings SR, Browner WS, Grady D, Hearst N, Newman TB, eds. Designing Clinical Research. Philadelphia, Lippincott Williams \& Wilkins, 2001; pp. 65-91. 